\title{
Characterization of Copper Adsorption on Oxidized Activated Carbon
}

\author{
João Paulo de Mesquita, Patrícia B. Martelli and Honória de Fátima Gorgulho* \\ Departamento de Ciências Naturais, Universidade Federal de São João del Rei, Campus Dom Bosco, \\ Praça Dom Helvécio, 74, 36301-160 São João Del Rei- MG, Brazil
}

\begin{abstract}
Esse artigo discute a adsorção de íon $\mathrm{Cu}$ (II) em carvão ativado oxidado com $\mathrm{HNO}_{3}$. As modificações introduzidas na superfície do carvão ativado (CA) foram caracterizadas por medidas de área superficial, espectroscopia de absorção no infravermelho, titulação pelo tradicional método de Boehm e titulação potenciométrica. Os dados da titulação potenciométrica foram ajustados através de um método não linear desenvolvido para determinar a concentração e distribuição do pKa dos sítios ácidos ionizáveis presentes na superfície do CA, antes e após a oxidação com $\mathrm{HNO}_{3}$. Os estudos de adsorção foram realizados em batelada para a faixa de concentração de 0,08 a $1,75 \mathrm{mmol} \mathrm{L}^{-1} \mathrm{em} \mathrm{pH}=4,0$. Os resultados mostraram que o tratamento do CA com ácido leva à diminuição na área superficial aparente e produz leves modificações na estrutura de poros. Entretanto, a oxidação influenciou fortemente a estrutura química da superfície do CA através do aumento na concentração de grupos ácidos com $\mathrm{pKa}<6$, causando assim uma melhora significativa na adsorção do íon $\mathrm{Cu}(\mathrm{II})$. A maior capacidade de adsorção do CA oxidado foi relacionada à presença de grupos ácidos com $\mathrm{pKa}<4$, revelando o importante papel destes grupos na adsorção pelo mecanismo de troca iônica.
\end{abstract}

This paper discusses $\mathrm{Cu}$ (II) ion adsorption onto oxidized activated carbon with $\mathrm{HNO}_{3}$. The modifications introduced on the activated carbon (AC) surface were characterized by surface area measurement, FT-IR spectroscopy, titration by the traditional Boehm procedure, and potentiometric titration. A nonlinear method for fitting acid-base potentiometric titration data was applied to determine the concentration and pKa distributions of the ionizable acidic sites on $\mathrm{AC}$, before and after $\mathrm{HNO}_{3}$ oxidation. Adsorption studies were conducted in batch mode for the concentration range 0.08 to $1.75 \mathrm{mmol} \mathrm{L}^{-1}$ and $\mathrm{pH}=4.0$. Results showed that the acid treatment of $\mathrm{AC}$ leads to a decrease in apparent surface areas and produces slight modifications in pore structure. However, oxidation strongly influenced the AC surface chemical structures by increasing the concentration of acidic groups with $\mathrm{pKa}<6.0$, which significantly improved $\mathrm{Cu}$ (II) ion adsorption. The uptake enhanced for oxidized carbon was related to the presence of acidic groups with pKa lower than 4 , revealing the important role of acidic groups in adsorption by ion-exchange mechanisms.

Keywords: activated carbon, copper adsorption, potentiometric titration

\section{Introduction}

In many countries, toxic heavy metals in wastewater have become an important concern lately because of their harmful environmental impact, which creates the need for water recycling. The presence of heavy metals in the environment can be detrimental to a variety of living species and copper is one of the most toxic metals to marine life and human beings. ${ }^{1}$ Environmental contamination due to copper is primarily caused by mining, printed circuits, metallurgical and fiber

*e-mail: gorgulho@ufsj.edu.br production, pipe corrosion, and metal plating industries. ${ }^{2}$ Agricultural inputs such as fertilizers, fungicidal sprays, and animal waste also lead to water pollution due to copper. Copper neurotoxicity has been reported to cause "Wilson's disease", which is characterized by copper build-up in the brain lenticular nucleons and by kidney failure. ${ }^{1}$ Therefore, the elimination of heavy metals such as copper from water and wastewater is important for public health.

Many methods have been proposed for the removal of heavy metals from water, including chemical precipitation, membrane filtration, ion exchange, and adsorption. ${ }^{3-5}$ Each method has merits and limitations. Adsorption processes 
are very versatile and efficient, and have received considerable attention in recent years. Activated carbon (AC) is an effective absorbent of many organic substances in water. In contrast to organic pollutants, AC does not remove water-dissolved metal ions and inorganic compounds effectively. The hydrophobic graphene layer makes its interaction with hydrated ions difficult. Therefore, the adsorption capacity and feasible removal rates must be substantially improved by the modification of the AC surface with suitable chemicals. ${ }^{6-8}$ For this reason, modification and impregnation techniques have been used to increase AC surface adsorption and removal capacity as well as to add selectivity to carbon.

However, ACs are not widely used due to their questionable regenerability, which depends on the mechanism of the metal ion adsorption. A variety of interactions between cationic species and the carbon surface might occur, such as, formation of surface complexes, ion-exchange processes, and redox reactions. Understanding the interaction of metal ions with the carbon surface is essential to control the sorption and desorption processes applicable to AC.

Previous investigations have demonstrated that the presence of oxygenated groups on the surface of AC favors metal adsorption through the formation of metal complexes. ${ }^{8}$ In general, this process is considered an ion exchange reaction with the participation of a strong acidic surface groups. ${ }^{9,10}$

[surface] $\mathrm{nH}^{+}+\mathrm{M}^{\mathrm{n}+}(\mathrm{aq}) \rightleftharpoons[$ surface $] \mathrm{M}^{\mathrm{n}+}+\mathrm{nH}^{+}(\mathrm{aq})$

AC chemical oxidation by nitric acids is one of the most effective means to provide acidic carboxylic and phenolic groups to AC surface. ${ }^{10,11}$ However, due to the carbon surface heterogeneity, the carboxylic group introduced exhibits a range of acid dissociation constants $(\mathrm{Ka})$, depending on the neighboring groups and the size of the graphene layer. As a result, the types of acidic groups (Ka) that display ion-exchange properties are insufficiently known. These difficulties are connected with the structural uncertainty of the adsorption sites on heterogeneous surfaces.

Determining the concentration and $\mathrm{Ka}$ of the acidic groups on the AC surface is the first step to characterize acidity, ion exchange capacity, and charge accumulation properties. Potentiometric titration is frequently used to study the acid-base properties of solid surfaces. ${ }^{12,13}$ Linear and non-linear numerical analysis techniques are commonly used in the treatment of potentiometric data for humic acids, proteins, and chitosan. ${ }^{14-16}$ The complexity of these equations has evolved along with computers and software and the calculation load.
The main objective of the present study was to investigate the relation between copper adsorption and desorption processes on activated carbon, and the nature (pKa) of the generated acidic sites on $\mathrm{AC}$ surface. $\mathrm{HNO}_{3}$ was used under reflux to oxidize the carbon surface. Oxidized $\mathrm{AC}$ was extracted with $\mathrm{NH}_{4} \mathrm{OH}$ instead of the typically used $\mathrm{NaOH}$. Washing with $\mathrm{NaOH}$ solutions effectively dissolves the soluble residues generated during oxidation; however, $\mathrm{Na}^{+}$ions cannot be completely eliminated during the thermal treatment and can remain in the micropores. ${ }^{17}$ In contrast, the use of $\mathrm{NH}_{4} \mathrm{OH}$ under reflux ensures that only $\mathrm{H}^{+}$and $\mathrm{OH}^{-}$ions occupy the surface acidic and basic sites after rinsing with water and drying at $100{ }^{\circ} \mathrm{C}$.

Potentiometric titration in aqueous medium and data numerical analysis by nonlinear regression techniques have been used in order to distinguish acidic groups with different $\mathrm{Ka}$ on AC. The model used in the present study is based on the studies of Masini and co-workers, ${ }^{18,19}$ which was developed for humic acids and polyelectrolytes. These authors assumed that the ionizable groups behave as a mixture of $\boldsymbol{N}$ monoprotic acids. Ka would be dependent not only on the chemical identity of the ionizable group, but also on the local interactions due to the chemical and physical media where the group is located on the surface of AC. The effects of charge accumulation on Ka were neglected in this model.

\section{Experimental}

\section{Materials}

Activated carbon (AC) (Fluka) was washed with distilled water and dried at $100{ }^{\circ} \mathrm{C}$ for 24 hours. Next, AC was cooled in a desiccator containing silica gel and stored in a bottle labeled Raw Activated Carbon (RAC). RAC was used to produce the oxidized activated carbon, named Modified Activated Carbon (MAC).

The copper solutions used in the equilibrium experiments were prepared with deionized water and $\mathrm{CuSO}_{4} \cdot 5 \mathrm{H}_{2} \mathrm{O}$ (Biotec). The analytic curve was obtained with Titrisol Merck solution. All chemicals were reagent grade.

\section{Preparation of MAC}

RAC was refluxed with an $\mathrm{HNO}_{3}$ (VETEC) solution $(50 \% \mathrm{~m} / \mathrm{v})$ at boiling temperature for 2 hours. Next, the oxidized carbon was washed with distilled water, followed by reflux of $1.0 \mathrm{~mol} \mathrm{~L}^{-1}$ of $\mathrm{NH}_{4} \mathrm{OH}$ (SINTH) solution for 1 hour. The AC sample prepared was rinsed in a Soxhlet 
extractor at $100{ }^{\circ} \mathrm{C}$ with distilled water for removal of the residual base and byproducts. The product (MAC) was dried at $100{ }^{\circ} \mathrm{C}$ for 24 hours.

\section{Textural properties}

Sample textural characterization was performed by $\mathrm{N}_{2}$ adsorption at $77 \mathrm{~K}$ in a NOVA $300 \mathrm{BET}$ analyzer (Quanta Chrome, USA). Pore size distributions were obtained by applying the density functional theory (DFT) method to $\mathrm{N}_{2}$ adsorption isotherms.

\section{FT-IR spectrum of AC}

Sample FT-IR spectra were recorded in a Perkin-Elmer 1720 FTIR spectrometer in the $350-4000 \mathrm{~cm}^{-1}$ wave number range. Powder samples were diluted in $\mathrm{KBr}$ (Merck for spectroscopy) in an approximate ratio of $1 / 500$. The resulting mixture was pressed into pellets and oven-dried at $110{ }^{\circ} \mathrm{C}$ for at least 20 hours. Spectra were obtained with 60 scans and resolution of $8 \mathrm{~cm}^{-1}$. The $\mathrm{KBr}$ spectra were subtracted as blank.

\section{Acid-base properties-Boehm titration method}

The method proposed by Boehm was used to estimate the acid-base properties of RAC and MAC samples. ${ }^{20}$ It is well known that surface chemical groups are more complex than shown by Boehm's titration, but this method gives a semi-quantitative measure of surface functionalities. Boehm's method is based on acid-base titration of carbon acidic or basic centers. Consequently, selective neutralization of surface groups by equilibration with a series of bases with increasing strength was conducted as follows: $\mathrm{NaHCO}_{3}$ neutralizes carboxylic groups; $\mathrm{Na}_{2} \mathrm{CO}_{3}$ neutralizes carboxylic groups and also allows lactonic groups to open and form carboxylic groups, which are then neutralized; $\mathrm{NaOH}$ neutralizes carboxylic, lactonic, and phenolic groups.

Four parts of carbon samples were weighed (about $0.2500 \mathrm{~g}$ each) and placed in four separate bottles. Next, $20 \mathrm{~mL}$ of $0.0500 \mathrm{~mol} \mathrm{~L}^{-1}$ of different bases, $\mathrm{NaHCO}_{3}$ (SINTH), $\mathrm{Na}_{2} \mathrm{CO}_{3}($ SINTH), and $\mathrm{NaOH}$ (MERCK), were transferred to bottles containing the previously weighted carbon samples. A blank was prepared for each experimental condition. The bottles were degassed with $\mathrm{N}_{2}$, closed and shaken for 48 hours. The solutions were then filtered and the amounts of each reagent adsorbed were determined by titration with $\mathrm{HCl} 0.0500 \mathrm{~mol} \mathrm{~L}^{-1}$. The procedure was repeated for two other amounts of carbon samples (0.1000 g).
Acid site concentration was calculated by the average of the amounts obtained for each mass: $\bar{c}=\frac{\left(\sum c_{i}\right)}{n}$, where "c bar" stands for the mean; $c_{i}$ is the value of each concentration; $n=3$ is the number of experiments. The standard deviation was obtained by: $S D=\sqrt{\frac{\sum\left(c_{i}-\bar{c}\right)^{2}}{n-1}}$.

\section{Potentiometric titration}

Potentiometric titration was performed in triplicate for each sample with three different amounts $(0.2500,0.1000$, and $0.0250 \mathrm{~g}$ ). The carbon mass was added to the electrochemical cell with $0.7 \mathrm{~mL} \mathrm{HCl} 0.1240 \mathrm{~mol} \mathrm{~L}^{-1}$ under $\mathrm{N}_{2}$ atmosphere and ionic force adjusted to $0.10 \mathrm{~mol} \mathrm{~L}^{-1}$ with $\mathrm{KCl}$, making a total volume of $20 \mathrm{~mL}$. The $\mathrm{pH}$ was monitored until equilibrium was reached; next, $\mathrm{NaOH}$ (MERCK) $0.0950 \mathrm{~mol} \mathrm{~L}^{-1}$ titration was started. The experiment was performed with an automatic micro burette system Titroline ALPHA (SCHOTT S.A.) interfaced with a microcomputer. Titration was conducted with $0.0100 \mathrm{~mL}$ injections at intervals of $100 \mathrm{~s}$.

\section{Potentiometric titration modeling}

The nonlinear regression program used in this work to fit potentiometric titration data makes use of a general equation that describes the titration of the mixture of a strong acid with $N$ weak acids (surface groups). ${ }^{18,19}$

$$
\begin{array}{r}
f\left(V, H^{+}\right)=\left(V i-V_{H A_{0}}\right) C b+\left\{\left[H_{i}^{+}\right]-\frac{K w}{\left[H_{i}^{+}\right]}\right\}\left(V_{0}+V i\right)- \\
\sum_{i=1}^{n}\left(V_{H A n}-V_{H A n-1}\right) \frac{K_{H A_{n}}}{\left(K_{H A_{n}}+\left[H_{i}^{+}\right]\right)} C b
\end{array}
$$

where $\left[\mathrm{H}^{+}{ }_{\mathrm{i}}\right]$ is the hydrogen ion concentration $\left(\left[\mathrm{H}^{+}{ }_{\mathrm{i}}\right]=\right.$ $\left.10^{\mathrm{pHi}}\right), V_{i}$ is the titrant volume added, and $V_{0}$ is the initial volume in the potentiometric cell before starting titration. $V_{H A O}$ is the equivalent volume for the excess strong acid. $V_{H A n}$ and $K_{H A n}$ are the equivalent volume and the ionization constant, respectively, for the $N$ acids present on the surface, and $\mathrm{Cb}$ is the base concentration $\left(\mathrm{mol} \mathrm{L}^{-1}\right)$. Through the minimization of the square sum $\mathrm{S}$ (error):

$$
S=\sum_{i=1}^{m}\left[p H_{i}(\operatorname{Exp})-p H_{i}(\text { calc })\right]^{2}
$$

where $\mathrm{m}$ is the total number of experimental data $(\mathrm{V}, p H)$, the parameters $\mathrm{V}_{\mathrm{HAn}}$ and $\mathrm{K}_{\mathrm{Han}}$ are adjusted. Calculation is started with the input of initial values of $\mathrm{V}_{\mathrm{HAn}}$ and $\mathrm{K}_{\mathrm{Han}}$ (guesses). With the PEGASO iteractive method, the best approximations for the $\mathrm{pH}_{i}(\mathrm{calc})$ values are obtained with the recurrence equation: ${ }^{21}$ 


$$
p H_{i, k+1}=p H_{i, k}-\frac{f\left(p H_{i, k}\right)\left(p H_{i, k}-p H_{i, k-1}\right)}{f\left(p H_{i, k}\right)-f\left(p H_{i, k-1}\right)} n=1,2,3 \ldots
$$

where the values of the functions $f\left(p_{i^{\prime} k-1}\right), f\left(p H_{i^{\prime} k}\right)$ and $p H_{i^{\prime} k-1}$ and $p H_{i^{\prime} k}$ are chosen according to the conditions:

$$
\begin{aligned}
& \text { if } f\left(p H_{i, k+1}\right) \cdot f\left(p H_{i, k}\right)<0 \text {, than } \\
& \quad\left[p H_{i, k-1} f\left(p H_{i, k-1}\right)\right] \text { is exchanged for }\left[p H_{i, k}, f\left(p H_{i, k}\right)\right] \\
& \text { if } f\left(p H_{i, k+1}\right) \cdot f\left(p H_{i, k}\right)>0 \text {, than } \\
& \quad\left[p H_{i, k-1} f\left(p H_{i, k-1}\right)\right] \text { is exchanged for }\left[p H_{i, k} f\left(p H_{i, k-1}\right)\right] \cdot \frac{f\left(p H_{i, k}\right)}{f\left(p H_{i, k}\right)+f\left(p H_{i, k+1}\right)}
\end{aligned}
$$

The iteractions are carried out until the condition $\left[\left(p H_{i, k+1}-p H_{i, k}\right) / p H_{i, k}\right]<0.00001$ reach the limit.

The obtained $\mathrm{H}^{+}$concentration relative to $\mathrm{pH}$ (calc) was corrected through the ion activity coefficient at the respective ionic force, resulting in the effective concentration (ion activity).

$$
a_{i}=C_{i} f_{i}
$$

where $C_{i}$ is the $\mathrm{H}^{+}$concentration and $f_{i}$ is the activity coefficient calculated with the equations:

$f_{i}=10^{-\left(\frac{0.512_{i}^{2} \sqrt{\mu}}{1+0.33 \alpha_{i} \sqrt{\mu}}\right)}$

(Debye-Hückel equation used for $\mu<0.20 \mathrm{~mol} \mathrm{~L}^{-1}$ )

$f_{i}=10^{\left.-\frac{0,51 Z^{2} \sqrt{\mu}}{1+0,3 \alpha_{i}, \sqrt{\mu}}-0,10 z_{i}^{2 \mu}\right)}$

(Davies equation used for $0.20<\mu<0.60 \mathrm{~mol} \mathrm{~L}^{-1}$ )

where $\alpha$ is the ion size in angstroms $\left(1.10^{-10} \mathrm{~m}\right), \mathrm{Z}$ is the ion charge, and $\mathrm{m}$ is the ionic force of the solution obtained with the equation $\mu=1 / 2 \sum_{i=1}^{n} C_{i} Z_{i}^{2}$. After calculating all $p H($ calc) values, equation (2) was used to obtain the $\mathrm{S}$ value.

The parameters $\mathrm{V}_{\mathrm{HAn}}$ and $\mathrm{K}_{\mathrm{Han}}$ were adjusted by the Gradient method, with which the shift value of each parameter $\mathrm{V}_{\mathrm{HAn}}$ and $\mathrm{K}_{\mathrm{Han}}$ initially guessed through equations 6 and 7 have been calculated:

$$
\begin{aligned}
& d V H A_{n}=\frac{-f^{\prime}\left(V_{H A n}\right)}{|\nabla|} x \Delta P \\
& d K H A_{n}=\frac{-f^{\prime}\left(K_{H A n}\right)}{|\nabla|} x \Delta P
\end{aligned}
$$

where $\Delta \mathrm{P}$ is a fixed parameter that determines the size of the step in the direction of the gradient vector. ${ }^{22}$ To calculate the value of $f^{\prime}\left(K_{H A n}\right)$ and $f^{\prime}\left(V_{H A n}\right)$, one of the parameters is incremented while all other parameters are kept constant. The process previously described is repeated for a new error-value calculation:
$S_{1}=\sum_{i=1}^{m}\left[p H_{i}(\operatorname{Exp})-p H_{i}(\text { calc })\right]^{2}$. This same procedure is conducted for all parameters to calculate the values of $\mathrm{S}_{2}$, $\mathrm{S}_{3}, \ldots, \mathrm{S}_{\mathrm{n}}$. The values of $f^{\prime}\left(K_{H A n}\right)$ and $f^{\prime}\left(V_{H A n}\right)$ are obtained with equations $\frac{S_{1}-S}{d x}, \frac{S_{2}-S}{d x}, \ldots, \frac{S_{n}-S}{d x}$, where $\mathrm{dx}$ is the increment value. The module of the gradient vector is calculated with the equation $|\nabla|=\sqrt{f^{\prime}\left(V H A_{0}\right)^{2}+\sum_{n=1}^{n} f^{\prime}\left(V H A_{n}\right)^{2}+\sum_{n=1}^{n} f^{\prime}\left(K H A_{n}\right)^{2}}$. Results of this equation are used to calculate the values of dVHAn and dKHAn, which, in turn, are used to update the values of $\mathrm{V}_{\mathrm{HAn}}$ and $\mathrm{K}_{\mathrm{Han}}$. Thus, by using these new values, the procedure described above is used again to obtain the values of $S, S_{1}, S_{2}, \ldots, S_{n}$ values. The calculation sequence is repeated until a minimum $S$ value is reached.

The program was developed in MATLAB 6.5.

\section{Adsorption isotherms}

Each isotherm point was determined using 0.5000 $\mathrm{g}$ of AC samples added to $50 \mathrm{~mL}$ of a copper solution of known concentration. The solution $\mathrm{pH}$ was adjusted by adding $\mathrm{H}_{2} \mathrm{SO}_{4}$ dropwise. The experiments were conducted at initial $\mathrm{pH}$ 4.0. Copper solution concentration was varied from 0.0850 to $1.7500 \mathrm{mmol}$ $\mathrm{L}^{-1}$. The bottles were placed on a shaker (TECNALTE-140) at $25^{\circ} \mathrm{C}$ for 24 hours. The initial and final solution concentrations were measured in an atomic absorption spectrometer VARIAN SpectrAA at 20-400 $\mathrm{nm}$. The final solution $\mathrm{pH}$ was also measured. One variation of this procedure was the addition of $\mathrm{Na}_{2} \mathrm{SO}_{4}$ to the copper solution to keep the ionic strength at 0.10 mol L $\mathrm{L}^{-1}$, that is to say, the experiment was also conducted with constant ionic strength.

\section{Desorption isotherms}

For the desorption study, AC samples slurries were filtered out of the isotherm adsorption copper solutions and rinsed with deionized water. The rinsed carbon was transferred to an Erlenmeyer flask with $50 \mathrm{~mL} \mathrm{HCl} 0.10$ mol L-1. The flasks were placed in the shaker at $25^{\circ} \mathrm{C}$ for 24 hours. The final solution concentrations were measured in an atomic absorption spectrometer VARIAN SpectrAA at 20-400nm.

\section{pH-monitored adsorption experiments}

The same procedure described for isotherm adsorption was also performed for $\mathrm{pH}$-monitored adsorption 
experiments; however, instead of shaking the bottle, the flasks were connected to a pHmeter Quimis 400ms with an $\mathrm{Ag} / \mathrm{AgCl}$ combination glass electrode. The system was assembled to automatically measure $\mathrm{pH}$ as a function of time during the entire adsorption process. In the end, $\mathrm{pH}$ of the AC/solution system was obtained before and after adsorption of copper for each concentration.

\section{Isotherm model}

Surface adsorption can be described by the association/ dissociation reaction:

$\mathrm{A}+\mathrm{B} \rightleftharpoons \mathrm{AB}$

where $\mathrm{A}$ represents the chemicals and $\mathrm{B}$ represents the adsorption centers in solid substrate. At low concentrations in a homogeneous system, the relation observed is:

$[\mathrm{AB}] \propto[\mathrm{A}]$

which can be described by the Langmuir isotherm:

$q=Q \frac{K C}{1+K C}$

where $\mathrm{q}$ is the concentration of adsorbate on the solid phase $\left(\mathrm{mmol} \mathrm{g}^{-1}\right), \mathrm{K}$ is the Langmuir constant $\left(\mathrm{L} \mathrm{mmol}^{-1}\right)$, which is a direct measure of adsorption intensity, also called affinity constant, Q is a constant related to the area occupied by an adsorbate monolayer reflecting maximum adsorption capacity $\left(\mathrm{mmol} \mathrm{g}^{-1}\right)$, and $\mathrm{C}$ is the equilibrium concentration in liquid phase $\left(\mathrm{mmol} \mathrm{L}^{-1}\right)$.

The Langmuir isotherm parameters $\mathrm{Q}$ and $\mathrm{K}$ were evaluated by using Microsoft Origin 6.1 (Northampton, MA, USA) nonlinear curve fitter, which minimizes the value of Chi-square by varying the fitting parameters. Chi-square is defined as: $\sum\left(\frac{y-y_{i}}{\sigma_{i}}\right)^{2}$, where $y$ is a fitted value (model value) for a given point, $y_{i}$ is the point measured datum value and $\sigma_{\mathrm{i}}$ is an estimate of the standard deviation for $y_{i}$. When Chi-square is minimized, the Coefficient of Determination $\left(\mathrm{R}^{2}\right)$ value tends to decrease to 1 . The parameter value and the standard error estimates were reported as calculated by the Origin program.

\section{Results and Discussion}

\section{Surface textural characteristics}

The surface area and porosity of the carbon materials used are compiled in Table 1. The acid treatment of RAC
Table 1. Summary of textural characterization

\begin{tabular}{lccc}
\hline Sample & $\begin{array}{c}\text { Area / } \\
\left(\mathrm{m}^{2} \mathrm{~g}^{-1}\right)\end{array}$ & $\begin{array}{c}\text { Average pore / } \\
\text { diameter }(\AA)\end{array}$ & $\begin{array}{c}\text { Total Pore / } \\
\text { volume }\left(\mathrm{cm}^{3} \mathrm{~g}^{-1}\right)\end{array}$ \\
\hline RAC & 770 & 34.39 & 0.65 \\
MAC & 670 & 31.21 & 0.52 \\
\hline
\end{tabular}

led to a decrease in apparent surface areas and also produced slight pore structure modifications.

As already reported by other studies, decreases in the BET surface area are due to blocking of the narrow pores by the surface complexes introduced by the nitric acid treatment. ${ }^{10}$ Therefore, $\mathrm{HNO}_{3}$ oxidation strongly influences the chemical structures of the AC surface as further discussed.

\section{Boehm's titration}

Changes on surface acidity due to the nitric acid treatment were quantified by Boehm's titration and are summarized in Table 2. The most usual sources of error in this method are sample heterogeneity and granulometry. However, because the samples used in this work have similar textural properties (Table 1) satisfactory result was obtained, Table 2.

Table 2. Result of acidity distribution from Boehm's titration

\begin{tabular}{|c|c|c|c|c|}
\hline \multirow[b]{2}{*}{ mass / (g) } & \multicolumn{4}{|c|}{ Acidic sites / $\left(\mathrm{mmol} \mathrm{g}^{-1}\right)$} \\
\hline & Carboxyl & Lactone & Phenol & Total acidic sites \\
\hline & & RAC & & \\
\hline 0.1000 & 0.04 & 0.05 & 0.18 & 0.27 \\
\hline 0.1050 & 0.05 & 0.06 & 0.27 & 0.38 \\
\hline 0.2500 & 0.06 & 0.14 & 0.31 & 0.51 \\
\hline \multirow[t]{2}{*}{ deviation } & $0.05 \pm 0.01$ & $0.08 \pm 0.05$ & $0.2 \pm 0.1$ & $0.4 \pm 0.1$ \\
\hline & & MAC & & \\
\hline 0.1000 & 0.30 & 0.19 & 1.10 & 1.59 \\
\hline 0.1024 & 0.28 & 0.16 & 0.95 & 1.39 \\
\hline 0.2530 & 0.32 & 0.20 & 1.18 & 1.70 \\
\hline $\begin{array}{l}\text { mean and } \\
\text { standard }\end{array}$ & & & & \\
\hline deviation & $0.30 \pm 0.02$ & $0.18 \pm 0.02$ & $1.1 \pm 0.1$ & $1.6 \pm 0.2$ \\
\hline
\end{tabular}

Interestingly, few carboxylic acids groups were detected on RAC surface by this method, whereas the MAC sample exhibited a significant amount of acidic centers ( $\mathrm{pKa} \leq 5.0$ ) introduced by $\mathrm{HNO}_{3}$ oxidation. Indeed, the oxidation treatment increased by fourfold the total number of acidic sites in MAC. It is clear, therefore, that the nature of the surface chemical structure of AC was significantly altered by the $\mathrm{HNO}_{3}$ and $\mathrm{NH}_{4} \mathrm{OH}$ treatments. 


\section{Fourier Transform Infrared analysis}

Fourier Transform Infrared (FT-IR) spectra of RAC and MAC (Figure 1) show two important regions; the first between 4000 and $2500 \mathrm{~cm}^{-1}$ and the second at a lower frequency, below $2000 \mathrm{~cm}^{-1}$. In the higher wavelength region, an absorption centered at $3420 \mathrm{~cm}^{-1}$ could be distinguished, typical of $\delta(\mathrm{OH})$, for both samples. This absorption can be attributed to the presence of phenolic, lactonic, and carboxylic groups. In spite of the regional strong interference of water absorption, which prevented us from drawing conclusions, some differences among the spectra are clearly shown.
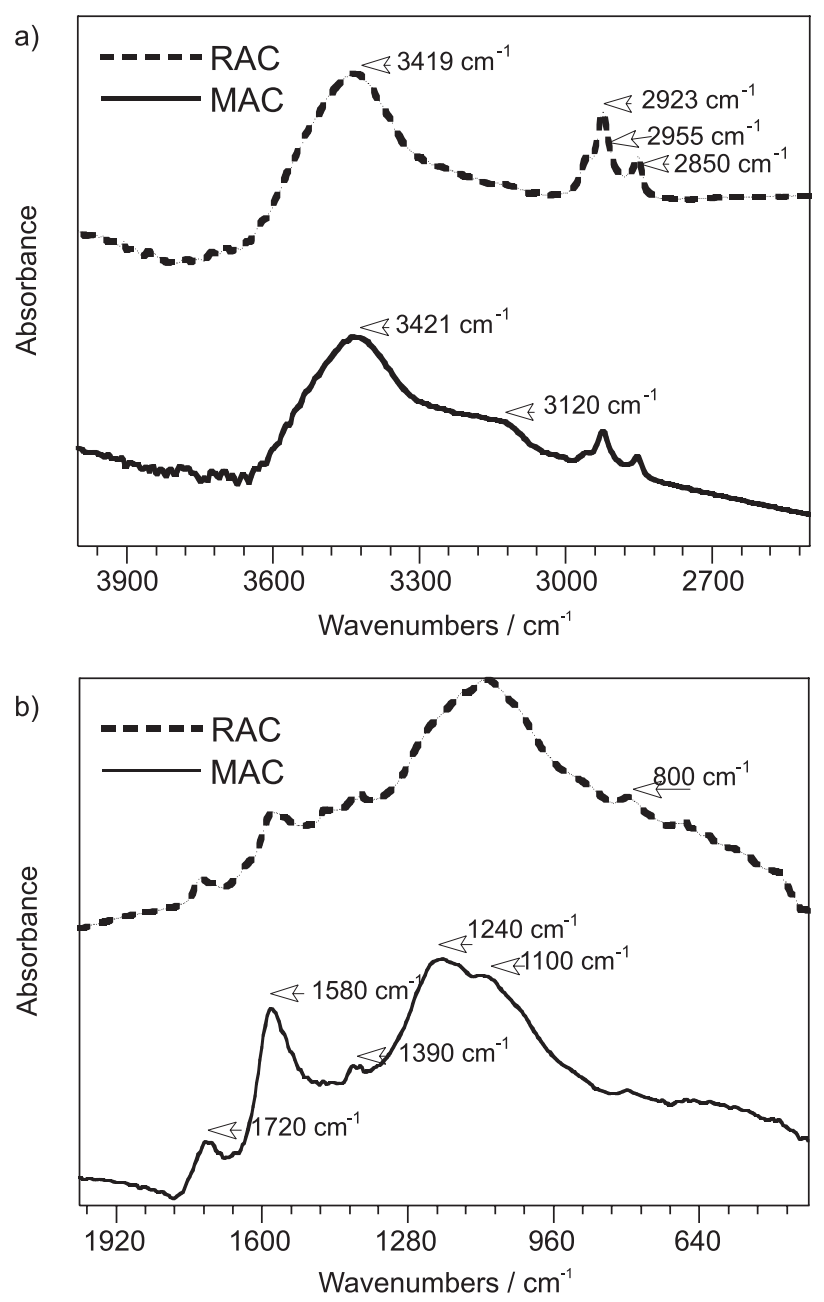

Figure 1. FT-IR spectra of RAC and MAC carbon samples. a) 4000 to $2500 \mathrm{~cm}^{-1}$ range and b) 2000 to $400 \mathrm{~cm}^{-1}$ range.

The presence of the carboxylic groups is usually confirmed by observing the stretching of these absorptions to lower energy values due to the hydrogen bond effect. This behavior is mainly observed for MAC samples, with a shoulder centered at $3120 \mathrm{~cm}^{-1}$ characteristic of the hydrogen bond of the carboxylic groups present on the surface. ${ }^{23}$ In addition, the broad band centered at $\approx 1100$ $\mathrm{cm}^{-1}$ and attributed to $\delta(\mathrm{OH})$ confirms the presence of phenolic and carboxylic structures in RAC and MAC samples.

The spectrum region is $1800-400 \mathrm{~cm}^{-1}$ where one normally observes the overlapping of several absorption bands that can be shifted to lower wavelengths by conjugation with the aromatic ring. In this range, the absorptions defined at $1734 \mathrm{~cm}^{-1}$ for RAC and at 1720 $\mathrm{cm}^{-1}$ for MAC are typical of the axial deformation of the $\mathrm{C}=\mathrm{O}$ groups. ${ }^{24}$ At this range, a second absorption typical of the $\mathrm{C}=\mathrm{C}$ bond in aromatic rings centered at $1580 \mathrm{~cm}^{-1}$ was observed for both samples.

Chingombe et al. ${ }^{25}$ reported that $\mathrm{HNO}_{3}$ oxidation introduces small amounts of nitrogen as $\mathrm{NO}_{2}$ groups, observed as pronounced peaks at $1240 \mathrm{~cm}^{-1}$ attributed to $v(\mathrm{C}-\mathrm{N})$ vibration. In accordance with these observations, the spectra of MAC at $1240 \mathrm{~cm}^{-1}$ showed a more pronounced band than the one observed for RAC in the same position, suggesting the presence of $v(\mathrm{C}-\mathrm{N})$ absorption of the $\mathrm{NO}_{2}$ group. The positively identification of its absorptions on the spectra is difficult because of several overlapping bands, such as $v(\mathrm{C}-\mathrm{O})$ and $\mathrm{v}(\mathrm{O}-\mathrm{H})$ vibrations.

In general, FT-IR results show that the RAC surface was modified by the introduction of carboxylic groups, as evidenced by the MAC spectrum.

\section{Potentiometric titration}

In potentiometric titration experiments, the time intervals between each titrant addition and tolerance of $\mathrm{pH}$ variation define a $\mathrm{pH}$ stability criterion that characterizes the severity imposed on ensuring equilibrium. ${ }^{26}$ The reproducibility of potentiometric titration results requires sufficiently long periods so as to ensure that acid-base equilibrium was reached. Thus, the best experimental conditions for the samples were studied first. In these experiments, the automatic titration procedure was studied as a function of the amount of sample, titrant dose, and time interval. After the preliminary tests, the time parameter of $100 \mathrm{~s}$ and titrant dose of $0.01 \mathrm{~mL}$ were fixed to perform the experiments. Figure 2 shows the raw titration data recorded as a function of the $\mathrm{HCl}$ volume added to MAC and RAC samples for duplicated experiments. It is clear in Figure 2 that stable and reproducible conditions were obtained in these conditions for both samples.

Sample mass impact on potentiometric titration was studied by means of experiments with different amount of $\mathrm{AC}$ and the non-linear program to calculate pka 

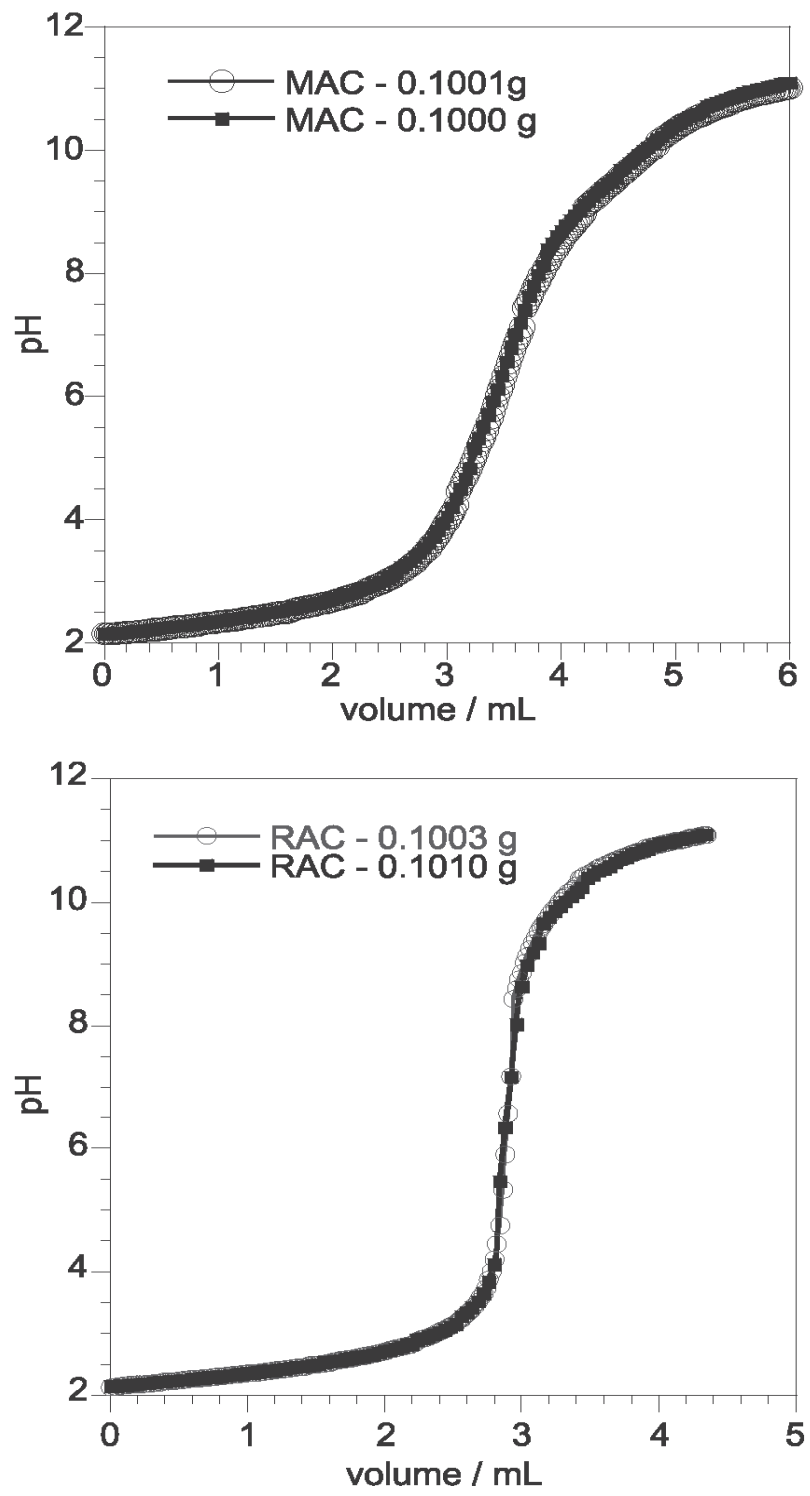

Figure 2. Potentiometric titrations curves obtained for each AC sample (RAC and MAC) in duplicate. distribution and acid concentration. The number of sites was based only on the statistical test described in equation 3. Fitting was started by assuming the presence of the three kinds of sites (carboxylic, lactones, and phenolic groups), based on Boehm's titration and FT-IR analyses. After the preliminary result, sites were added to the model until no statistically significant improvement was observed. The results obtained by fitting the experimental data are presented in Table 3. Notice that for the same samples the pKa distributions obtained by fitting are independent of the mass amount, which adds credibility to the measurement.

However, Table 3 shows that the acid site concentration increased slightly as the sample amount reduced. Such a behavior can be caused by high sample dilution associated with mass decrease. Thus, the equilibrium condition may be enhanced by additional contact between sample and solution. However, the total concentrations of acid groups determined for each AC were very similar and reflects the reproducibility and accuracy of the potentiometric titrations measurement.

Figure 3 shows the experimental and fitted (nonlinear method) potentiometric titration curves of RAC and MAC samples. It is important to note that the titration curves (experimental and calculated) overlapped fairly well. The observed MAC titration curves had a larger buffer zone than RAC as a result of the increase in acidic sites concentrations.

Table 3 shows that in pKa range lower than 6.0, RAC and MAC samples were characterized by similar acid strength distribution but different number of acid sites concentration. In this $\mathrm{pKa}$ range, acid concentration increased approximately fourfold for MAC in relation to RAC. On the other hand, for $\mathrm{pKa}$ range higher than 7.0,

Table 3. Result of nonlinear regression fitting for potentiometric titration curves

\begin{tabular}{|c|c|c|c|c|c|c|c|}
\hline \multirow[b]{2}{*}{ mass / (g) } & \multicolumn{5}{|c|}{$\begin{array}{l}\text { Functional groups content / }\left(\mathrm{mmol} \mathrm{g}^{-1}\right) \\
\text { pKa interval }\end{array}$} & \multirow[b]{2}{*}{$9.6-10.5$} & \multirow[b]{2}{*}{ total acidic site } \\
\hline & $2.5-4.5$ & $4.6-6.0$ & $6.1-7.0$ & $7.1-8.5$ & $8.6-9.5$ & & \\
\hline \multicolumn{8}{|c|}{ RAC } \\
\hline 0.2500 & 0.12 & 0.11 & - & - & - & 0.36 & 0.59 \\
\hline 0.1010 & 0.10 & 0.11 & - & - & - & 0.30 & 0.51 \\
\hline 0.0212 & 0.21 & 0.10 & - & - & - & 0.21 & 0.52 \\
\hline $\begin{array}{l}\text { mean and standard } \\
\text { deviation }\end{array}$ & $0.14 \pm 0.06$ & $0.11 \pm 0.01$ & - & - & - & $0.30 \pm 0.07$ & $0.5 \pm 0.1$ \\
\hline \multicolumn{8}{|c|}{ MAC } \\
\hline 0.2502 & 0.51 & 0.42 & - & - & 0.57 & 0.97 & 2.47 \\
\hline 0.1001 & 0.52 & 0.42 & - & - & 0.56 & 0.98 & 2.48 \\
\hline 0.0224 & 0.67 & 0.31 & - & - & 0.73 & 1.06 & 2.77 \\
\hline $\begin{array}{l}\text { mean and standard } \\
\text { deviation }\end{array}$ & $0.57 \pm 0.09$ & $0.38 \pm 0.06$ & - & - & $0.62 \pm 0.09$ & $1.00 \pm 0.05$ & $2.6 \pm 0.2$ \\
\hline
\end{tabular}




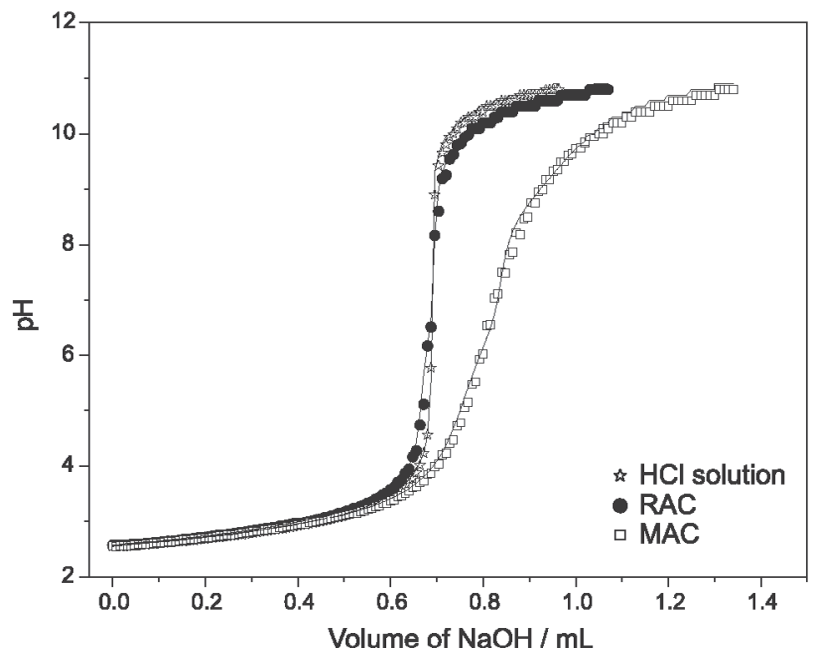

Figure 3. Potentiometric titration curves obtained by employing masses of approximately $0.0220 \mathrm{~g}$ for the $\mathrm{AC}$ samples. The solid line represents the curve obtained by the program used in this work.

the distribution of acid sites of the MAC sample was divided into two groups as follows: pKa range 9.6-10.5, which is also observed for RAC, and pKa range 8.5-9.5, not observed for RAC.

If the surface groups are expected to have acid strengths similar those of the organic acids with similar structures, the acid strengths of various organic acids can be referred for evaluation of the chemical structures on AC surface. The acid strengths of carboxylic acids such as benzoic acid, toluic acids, and some other aromatic carboxylic acids have a pKa around 5.0. Phenols such as phenol, pyrocatechols, and naphthols have a pKa above 9.0. However, the acid strength of these organic groups can be intensified by electrophilic substitution in the aromatic ring. This considerations suggest that the acidic groups on AC samples could be properly classified into two groups; the strong acids (for pKa range lower than 6.0), mainly comprising carboxylic acids, and the weak acids (with pKa higher than 7.0), comprising phenolic hydroxides.

\section{Copper adsorption isotherms}

Metal ions exist not only as single components but also as several species in solution, which leads to adsorption interference and competition phenomena. Therefore, soluble metal species that predominate in aqueous solutions should be evaluated before $\mathrm{Cu}$ (II) ion adsorption on $\mathrm{AC}$ is investigated.

Species percent concentration was found at working $\mathrm{pH}$ and concentration with the software VISUAL MINTEQ. ${ }^{27}$ Figure 4 illustrates the distribution of predominant copper species in aqueous solution at $\mathrm{pH}$ 4.0 for different concentration values.
According to the speciation result for $\mathrm{pH} 4.0$, the hexaquo $\mathrm{Cu}$ (II) complex was the predominant species at the isotherm concentration range. On the other hand, sulfate concentration increases with the addition of $\mathrm{Na}_{2} \mathrm{SO}_{4}$ salt led to increase the concentration of $\mathrm{CuSO}_{4}$ species, Figure 5. Consequently, the effect of the common ion can modify the distribution profile of the metal species in solution as well as interfere in the adsorption mechanism.

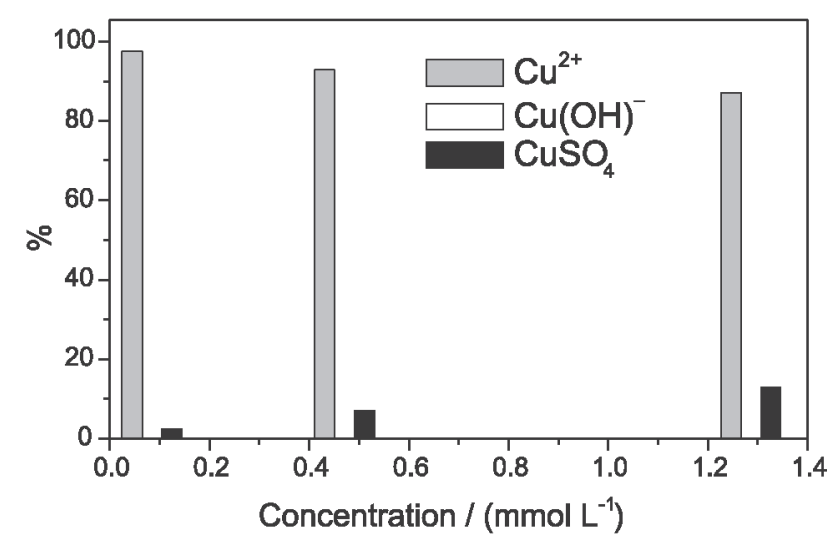

Figure 4. Predominant species calculated by VISUAL MINTEQ for $\mathrm{CuSO}_{4}$ solutions, $\mathrm{pH}=4$. Abscissa: total $\mathrm{Cu}$ (II) ion concentration. Ordinate: species percent.

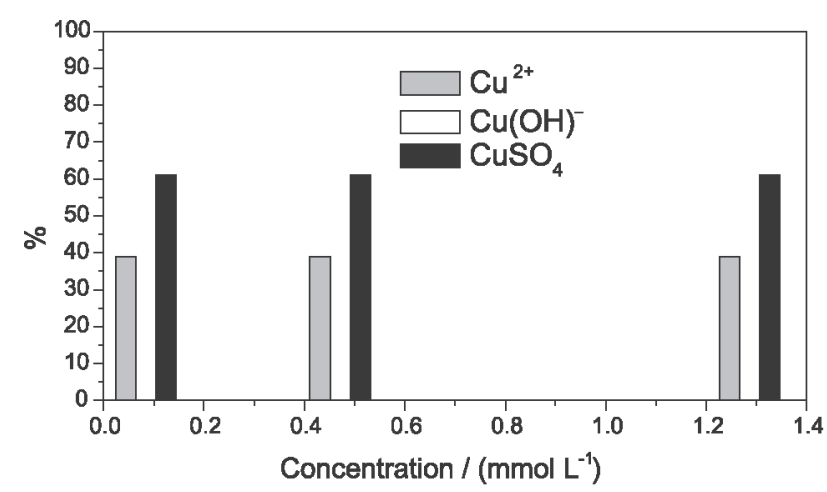

Figure 5. Predominant species calculated by VISUAL MINTEQ for $\mathrm{CuSO}_{4}$ solutions, with $\mathrm{Na}_{2} \mathrm{SO}_{4}$ added. Abscissa: total $\mathrm{Cu}$ (II) ion concentration. Ordinate: species percent.

\section{Adsorption isotherms}

RAC and MAC sample $\mathrm{Cu}$ (II) ion adsorption isotherms were obtained with and without $0.10 \mathrm{~mol} \mathrm{~L}^{-1}$ $\mathrm{Na}_{2} \mathrm{SO}_{4}$ to vary the solution ionic strength. All isotherms and the Langmuir equation fitting are depicted in Figure 6. The parameters obtained with Langmuir's model are summarized in Table 4. These data show that AC oxidation largely increased $\mathrm{Cu}$ (II) uptake despite the decrease in surface area and porosity. The same behavior was found for other oxidized carbon and metal ion systems. ${ }^{28,29}$ 


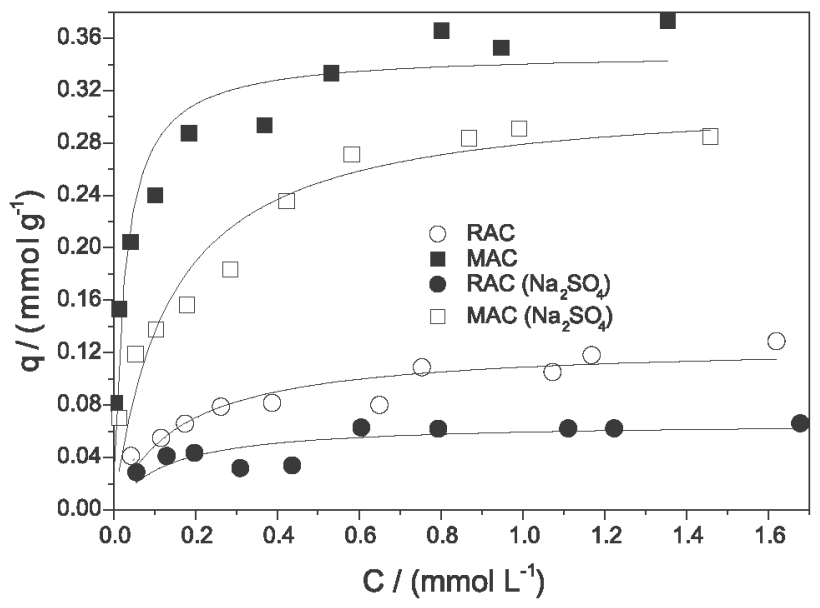

Figure 6. Adsorption isotherm of $\mathrm{Cu}(\mathrm{II})$ ions on activated carbon in absence and presence of $0.10 \mathrm{~mol} \mathrm{~L}^{-1} \mathrm{Na}_{2} \mathrm{SO}_{4}$. Abscissa: $\mathrm{C}=$ equilibrium concentration of metal in aqueous phase. Ordinate: $\mathrm{q}=$ concentration of metal ion in the carbon phase, in $\mathrm{mmol} \mathrm{g}^{-1}$. Solid line represents the Langmuir equation fitting.

Table 4. Result from Langmuir equation applied to adsorption isotherm of $\mathrm{Cu}$ (II) ion on RAC and MAC samples

\begin{tabular}{lccc}
\hline Sample & $\mathrm{Q} /\left(\mathrm{mmol} \mathrm{g}^{-1}\right)$ & $\mathrm{K} /\left(\mathrm{L} \mathrm{mmol}^{-1}\right)$ & $\mathrm{R}^{2}$ \\
\hline RAC & $0.102 \pm 0.009$ & $6 \pm 2$ & 0.86 \\
MAC & $0.36 \pm 0.02$ & $39 \pm 11$ & 0.90 \\
\hline \multicolumn{4}{c}{ With $\mathrm{Na}_{2} \mathrm{SO}_{4}$} \\
\hline RAC & $0.066 \pm 0.007$ & $8 \pm 4$ & 0.62 \\
MAC & $0.27 \pm 0.02$ & $7 \pm 2$ & 0.92 \\
\hline
\end{tabular}

Maximum copper adsorption capacity values $(\mathrm{Q})$ on MAC and RAC samples in the absence of $\mathrm{Na}_{2} \mathrm{SO}_{4}$ (Table 4 ) were $\approx 3.5$ times greater for MAC than for the untreated sample, as a consequence of proportional increase in acidity. The correlation between the increase in the number of acid sites (380\%) for a $\mathrm{pKa}<6.0$ and the increment in adsorption capacity of MAC (350\%) is noteworthy.

Langmuir constant values, $\mathrm{K}$, were larger for MAC than for RAC, probably due to the largest affinity between MAC surfaces and copper ions. At first, the standard deviation observed for this parameter may seem very high, however, it must be noted that the $\mathrm{K}$ value given in Table 4 was obtained for a larger concentration range, covering low concentrations, whose affinity is high, and for high concentrations, whose surface saturation decreases the affinity between the $\mathrm{Cu}$ (II) ion and the surface. This was particularly important for RAC, because its saturation occurred at lower concentrations than those of MAC. Thus, it is important to understand that the accuracy of the parameters in Table 4 must be evaluated with respect to the concentration window. Therefore, the parameter fitting standard errors are not excessively large because the Langmuir isotherm was fitted to both saturation and sub-saturation regions.
The effect of $\mathrm{Na}_{2} \mathrm{SO}_{4}$ addition on the adsorption isotherms shows that adsorption capacity decreased sharply for both samples (Table 4). It is interesting that the MAC affinity constant $(\mathrm{K})$ was also significantly affected by the presence of $\mathrm{Na}_{2} \mathrm{SO}_{4}$. The ionic solution strength is a key factor in the control of electrostatic interactions because of a screening effect of the surface charge produced by the added salt. Attraction or repulsion interactions can be reduced increasing the ionic strength of the solution. ${ }^{28}$

However, as the copper speciation with VISUAL MINTEQ programmer has shown, $\mathrm{Cu}^{2+}$ availability in solution containing $\mathrm{Na}_{2} \mathrm{SO}_{4}$ decreased at the concentrations used in this study (Figure 5). For example, for a copper concentration of $8.47310^{-5} \mathrm{~mol} \mathrm{~L}^{-1}$, the availability of hexaquo $\mathrm{Cu}^{2+}$ complex in solution was almost $100 \%$ in contrast to $39 \%$ in an aqueous solution of $\mathrm{Na}_{2} \mathrm{SO}_{4} 0.10$ mol L-1 This suggests that copper adsorption can also decreases due to the availability of hydrolyzed $\mathrm{Cu}^{2+}$, this species probably being the main form adsorbed on the surface.

\section{Copper adsorption mechanism}

The role of the carboxylic group in the copper adsorption on $\mathrm{AC}$ was investigated by $\mathrm{pH}$ monitoring during the adsorption process.

The experiments evidenced a decrease in $\mathrm{pH}$ along the adsorption process, especially for MAC, whose ratio between released and adsorbed copper protons was around 1, as shown in Figure 7.

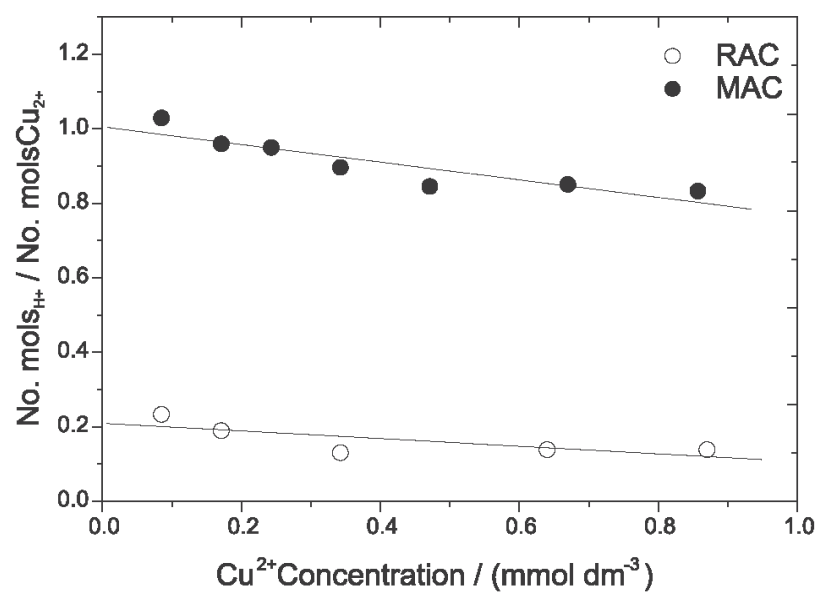

Figure 7. Ratio of $\mathrm{H}^{+}$released and $\mathrm{Cu}(\mathrm{II})$ uptake as a function of equilibrium concentration in $\mathrm{mmol} \mathrm{L}^{-1}$.

MAC was characterized by a large number of acidic sites that could be the centers responsible for proton release. More specifically, the adsorption of metal ions on MAC is probably conducted by ion exchange 
mechanism involving protonated surface sites. Other researchers have observed similar correlations between released protons and metal ions adsorbed on $\mathrm{AC} .{ }^{30}$ Copper ion uptake is thought to result from the formation of single metal-complexes, as suggested by equation 11 :

$\mathrm{S}-\mathrm{COOH}+\mathrm{Cu}^{2+} \rightleftharpoons \mathrm{S}^{-} \mathrm{COO}^{-} \mathrm{Cu}^{2+}+\mathrm{H}^{+}$

where $\mathrm{S}$ - $\mathrm{COOH}$ represents a carboxyl group on the surface. ${ }^{9,30,31}$ The mechanism above is favored by the acidic centers with small pKa values, as strong acid groups release protons more easily. Therefore, copper ion adsorption is mainly due to the strong dependence on the dissociation of surface acidic groups in the solution $\mathrm{pH}$. As the experiment was performed at $\mathrm{pH} 4.0$ (Figure 7), only the acidic groups with $\mathrm{pKa} \leq 4.0$ are able to provide metal binding sites for ion exchange reaction. In this way, carboxylic groups could provide additional ion binding capacity at $\mathrm{pH}=4.0$.

At high concentration, the calculated $\mathrm{nH}^{+} / \mathrm{nCu}^{2+}$ ratio becomes smaller than unity and decreases with the increase in solution concentration. This probably occurs because the basic sites on the $\mathrm{AC}$ surface also compete for $\mathrm{H}^{+}$and because there is more than one adsorption mechanism in action.

In the case of RAC, monitoring $\mathrm{pH}$ as a function of adsorption revealed that the ratio between released protons and adsorbed copper is close to 0.2. This means that the acid groups had no significant participation in RAC copper adsorption. Considering that the sample was characterized by few surface acidic groups, the graphene layer probably controlled the adsorption mechanism. The graphene layers, $\mathrm{C}_{\pi}$, act as Lewis basic centers, where protonation takes place according the equation 12 :

$-\mathrm{C}_{\pi}+2 \mathrm{H}_{2} \mathrm{O} \rightleftharpoons-\mathrm{C}_{\pi} \mathrm{H}_{3} \mathrm{O}^{+}+\mathrm{OH}^{-}$

These $-\mathrm{C}_{\pi}$ basic centers may also interact with metal cations. Indeed, some authors suggest that the adsorption of metal cation on nonoxidized carbons occurs mainly through $\mathrm{C}_{\pi}$-cation interactions..$^{28,32}$

\section{Copper desorption}

Considering that copper adsorption is based on a general ion-exchange reaction between $\mathrm{H}^{+}$and $\mathrm{Cu}^{2+}$, as suggested by equation 11 , the desorption process must be favored by the decrease in solution $\mathrm{pH}$. Therefore, the desorption experiment was performed with an $\mathrm{HCl}$ solution $0.10 \mathrm{~mol} \mathrm{~L}^{-1}$. The results given in Figure 8 show the desorption percentage for different initial copper concentrations.

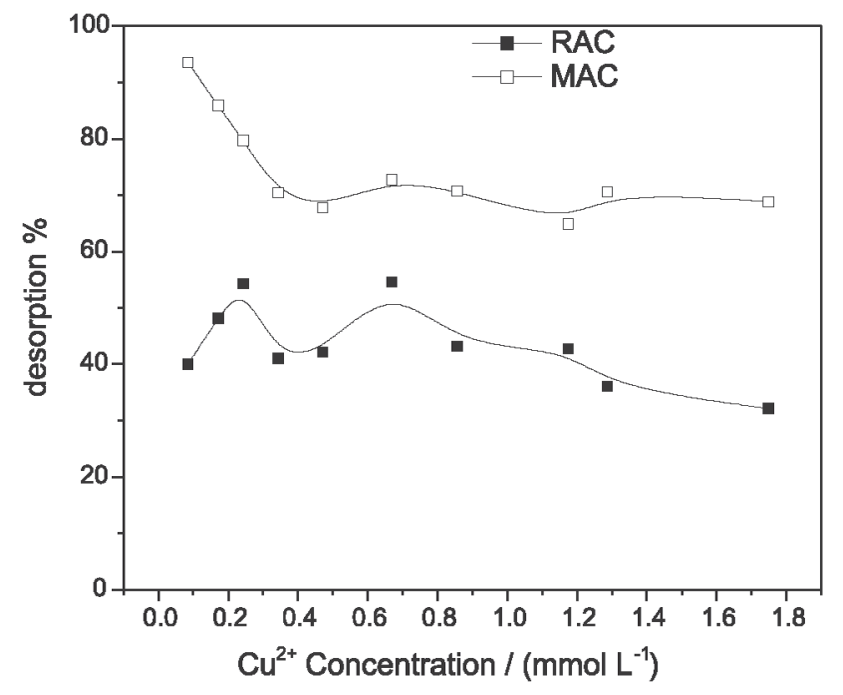

Figure 8. Recovery percentage of $\mathrm{Cu}(\mathrm{II})$ from desorption experiments using $0.10 \mathrm{~mol} \mathrm{~L}^{-1} \mathrm{HCl}$ solution.

According to the result observed for MAC sample, it is possible to remove almost $100 \%$ of the copper previously adsorbed at low concentrations and regenerate the carbon adsorbent. However, as concentration increases, the desorption decreases to $70 \%$. In Figure 7 the ratio of adsorbed copper to released proton was close to unity, mainly at low concentration, supporting an ion exchange mechanism as suggested by equation 11 . The same experiments showed that as concentration increases the ratio becomes lower than unity. This observation suggests that for MAC at least $70 \%$ of the desorption involved a reversible ion exchange mechanism. At low concentrations, these sites were more available on the surface and desorption is close to $100 \%$. For concentrations at which the surface is saturated and adsorption is close to the maximum coverage capacity (Q), other parallel mechanisms also occurred and copper desorption decreased.

For the nonoxidized carbon, RAC, desorption remained practically at $40 \%$. In this case, the reversible adsorption can derive from the same contribution of the small amount of acidic groups on the carbon surface to the ion exchange process.

\section{Conclusions}

This study show that $\mathrm{AC}$ oxidation with $\mathrm{HNO}_{3}$ leads to a significant increase in the amount of surface acid groups with the acid dissociation constant, Ka, distributed over a wide $\mathrm{pKa}$ range. These modifications do not relate to any noticeable change on specific surface area and porosity values, but improve the adsorption capacity of copper ions on oxidized AC. The application of Langmuir 
isotherms to experimental data shows that copper adsorption increases 3.5-fold for MAC, the oxidized sample, as compared with data for RAC. Experiments conducted in this work show that the maximum copper adsorption capacity depends on the ionic strength and the predominant copper species in the aqueous solution.

The results also support the hypothesis that AC oxidation improves copper adsorption by ion-exchange reaction, which can be attributed to the larger number of acidic sites on MAC with pKa range lower than 6 . The reversible copper adsorption occurs through the strongest acidic center with the displacement of one $\mathrm{H}^{+}$ion per adsorbed $\mathrm{Cu}$ (II) ion. At high $\mathrm{Cu}$ (II) concentration other mechanism can take place, which explain the $\mathrm{Cu}$ (II) ion desorption decreased when metal ion concentration increase. For the RAC, sample nonoxidized, copper adsorption was controlled by the Lewis basic center interactions.

The informations obtained in the present study will permit us to optimise the preparation of carbons adsorbent with reversible adsorption properties and improve $\mathrm{AC}$ regenerability.

\section{Acknowledgments}

This work was supported by FINEP- Financiadora de Estudos e Projetos - Ministério da Ciência e Tecnologia Project 01.03.0310.00. CNPq-PIBIC-UFSJ. FAPEMIGCEX-366/03.

\section{References}

1. Cai, L.; Li, X. K.; Song, Y.; Cherian, M. G.; Curr. Med. Chem. 2005, 12, 2753.

2. Robinson, P.; MacDonell, M.; Environ. Toxicol. Pharmacol. 2004, 18, 201.

3. Sikdar, K. S.; Buckle, J.; Rogut, J.; Environ. Prog. 2001, $20,1$.

4. Johns, M. M.; Marshall, W. E.; Toles, A. C.; J. Chem. Technol. Biotechnol. 1998, 71, 131.

5. Costa, L. C. M.; Araujo, M. H.; Sapag, K.; Sardella, M. F.; Silva, H.; Deiana, A. C.; Lago, R. M.; J. Braz. Chem. Soc. 2005, $16,899$.

6. Chen, P. J.; Wu, S.; Chong, K.; Carbon 2003, 41, 1979.

7. Pesavento, M.; Profumo, A.; Alberti, G.; Conti, F.; Anal. Chim. Acta 2003, 480, 171.
8. Chen, J.; Yiacoumi, S.; Blaydes, T. G.; Sep. Technol. 1996, 6, 133.

9. Chen, J. P.; Lin, M.; Carbon 2001, 39, 1491.

10. Noh, J. S.; Schawrs, J. A.; Carbon 1990, 28, 675.

11. Shim, J.; Park, S.; Ryu, S.; Carbon 2001, 39, 1635.

12. Jr, V. S.; Malik, D. J.; Streat, M.; Carbon 2002, 40, 95.

13. Shunkevich, A. A.; Akulich, Z. I.; Mediak, G. V.; Soldatov, V. S.; React. Funct. Polym. 2005, 63, 27.

14. Aleixo, L. M.; Godinho, O. E. S.; Costa, W. F.; Anal. Chim. Acta 1992, 257, 35.

15. Masini, J. C.; Godinho, O. E.; Aleixo, L. M.; Fresenius' J. Anal. Chem. 1998, 360, 104.

16. Jiang, X.; Chen, L.; Zhong, W.; Carbohydr. Polym. 2003, 54, 457.

17. Wu, Z.; Pittman, C. J.; Gardner, S. D.; Carbon 1995, 33, 597.

18. Masini, J. C.; Abate, G.; Lima, E. C.; Hahn, L. C.; Nakamura, M. S.; Lichtig, J.; Nagatomy, H. R.; Anal. Chim. Acta 1998, $364,223$.

19. Masini, J. C.; Anal. Chim. Acta 1993, 283, 803.

20. Boehm, H. P. In Chemical Identification of Functional Groups, Advances in Catalysis; Eley, D. D., ed.; Academic Press: New York, 1966, vol. 16, p. 179.

21. Barroso, L. C.; Cálculo Numérico com Aplicações, $2^{\text {nd }}$ ed., Harbra: São Paulo, 1987.

22. Bajpai, A. C.; Matemática Avançada para Engenharia, Cremus: São Paulo, 1980.

23. Serrano, G. V.; Almeida, F. P.; Valle, C. J. D.; Villegas, J. P.; Carbon 1999, 37, 1517.

24. Silverstein, R. M.; Bassler, G. C.; Morrill, T. C.; Identificação Espectrométrica de Compostos Orgânicos, $5^{\text {th }}$ ed., Guanabara Koogan: Rio de Janeiro, 1994.

25. Chingombe, P.; Saha, B.; Wakeman, R. J.; Carbon 2005, 43, 3132.

26. Contescu, A.; Contescu, C.; Putyera, K.; Carbon 1997, 35, 83.

27. Kocaoba, S.; Akcin, G.; Talanta 2002, 57, 23.

28. Álvarez-Merino, M. A.; Lópes-Ramon, V.; Castilha-Moreno, C. J.; J. Colloid Interface Sci. 2005, 288, 335.

29. Biniak, S.; Pakula, M.; Szymanski, G. S.; Swiatkowski, A.; Langmuir 1999, 15, 6117.

30. Dastgheib, S. D.; Rockstraw, D. A.; Carbon 2001, 39, 1849.

31. Corapcioglu, M. O.; Huang, C. P.; Water Res. 1987, 21, 1031.

32. Leon y Leon, C. A.; Solar J. M.; Calemma, V.; Radovic, L. R.; Carbon 1992, 30, 797. 